(c) Cambridge University Press 2015. This is an Open Access article, distributed under the terms of the Creative Commons Attribution licence (http://creativecommons.org/licenses/by/3.0/), which permits unrestricted re-use, distribution, and reproduction in any medium, provided the original work is properly cited.

\title{
Sampling strategies for phlebotomine sand flies (Diptera: Psychodidae) in Europe
}

\author{
B. Alten ${ }^{1}$, Y. Ozbel ${ }^{2}$, K. Ergunay ${ }^{3}$, O.E. Kasap ${ }^{1}$, B. Cull ${ }^{4}$, \\ M. Antoniou ${ }^{5}$, E. Velo ${ }^{6}$, J. Prudhomme ${ }^{7}$, R. Molina ${ }^{8}$, \\ A.-L. Bañuls ${ }^{7}$, F. Schaffner ${ }^{9}$, G. Hendrickx ${ }^{9}$, W. Van Bortel ${ }^{10}$ \\ and J.M. Medlock ${ }^{4 *}$
}

${ }^{1}$ Hacettepe University (HUESRL), Ankara, Turkey: ${ }^{2}$ Ege University (EGE), Izmir, Turkey: ${ }^{3}$ Hacettepe University, Medical Faculty (HU-MED), Ankara, Turkey: ${ }^{4}$ Medical Entomology group, Emergency Response Department, Public Health England, Salisbury, UK: ${ }^{5}$ University of Crete (UoC), Heraklion, Greece: ${ }^{6}$ Institute of Public Health (IPH), Tirana, Albania: ${ }^{7}$ UMR MIVEGEC (IRD 224 - CNRS 5290 - Universités Montpellier 1 et 2), Institut de Recherche pour le Développement (IRD), Montpellier, France: ${ }^{8}$ Instituto de Salud Carlos III (ISCIII), Madrid, Spain: ${ }^{9}$ Avia GIS, Zoersel, Belgium: ${ }^{10}$ ECDC, Stockholm, Sweden

\begin{abstract}
The distribution of phlebotomine sand flies is widely reported to be changing in Europe. This can be attributed to either the discovery of sand flies in areas where they were previously overlooked (generally following an outbreak of leishmaniasis or other sand fly-related disease) or to true expansion of their range as a result of climatic or environmental changes. Routine surveillance for phlebotomines in Europe is localized, and often one of the challenges for entomologists working in non-leishmaniasis endemic countries is the lack of knowledge on how to conduct, plan and execute sampling for phlebotomines, or how to adapt on-going sampling strategies for other haematophagous diptera. This review brings together published and unpublished expert knowledge on sampling strategies for European phlebotomines of public health concern in order to provide practical advice on: how to conduct surveys; the collection and interpretation of field data; suitable techniques for the preservation of specimens obtained by different sampling methods; molecular techniques used for species identification; and the pathogens associated with sand flies and their detection methods.
\end{abstract}

Keywords: Phlebotomus, sand flies, Europe, sampling

(Accepted 24 January 2015; First published online 14 August 2015)

\section{Introduction}

The phlebotomine sand flies (Diptera: Psychodidae, Phlebotominae) are vectors of several infectious pathogens

*Author for correspondence

Phone: +44 (0) 1980612100

E-mail: jolyon.medlock@phe.gov.uk causing leishmaniases, bartonellosis and arbovirus infections due to phleboviruses. Several of these diseases have wide geographical distributions around the world, and give rise to occasional epidemic outbreaks. In numerous countries, increasing risk factors are making sand fly-borne diseases a major public and veterinary health problem (Dedet, 2008). Among the 800 known species of sand fly, about 70, belonging to the genus Phlebotomus in the Old World and Lutzomyia in the New World, are proven or suspected vectors of pathogens. 
Table 1. Guide to sand fly sampling strategy.

\begin{tabular}{|c|c|c|c|}
\hline I want to & Purpose & Suggested trapping method(s) & Also see \\
\hline \multirow[t]{6}{*}{ Collect adults } & $\begin{array}{l}\text { Catalogue species present in } \\
\text { the study area }\end{array}$ & $\begin{array}{l}\text { Light traps, sticky traps, human landing } \\
\text { catches, flight traps }\end{array}$ & $\begin{array}{l}\text { Sampling strategy; handling and pro- } \\
\text { cessing; identification }\end{array}$ \\
\hline & Test for pathogens & $\begin{array}{l}\text { Light traps, sticky traps, resting site } \\
\text { collections }\end{array}$ & Sampling strategy; pathogen detection \\
\hline & Preservation and display & Resting site collections, animal-baited traps & $\begin{array}{l}\text { Sampling strategy; handling and pro- } \\
\text { cessing; identification }\end{array}$ \\
\hline & Collect live specimens & $\begin{array}{l}\text { Resting site collections, animal-baited traps, } \\
\text { human landing catches }\end{array}$ & $\begin{array}{l}\text { Sampling strategy; handling and } \\
\text { processing }\end{array}$ \\
\hline & Identify breeding areas & $\begin{array}{l}\text { Emergence traps, soil screening and sugar } \\
\text { flotation }\end{array}$ & Sampling strategy \\
\hline & Determine host preference & $\begin{array}{l}\text { Animal/human-baited traps, human land- } \\
\text { ing catches }\end{array}$ & $\begin{array}{l}\text { Identification; handling and } \\
\text { processing }\end{array}$ \\
\hline $\begin{array}{l}\text { Collect immature } \\
\text { stages }\end{array}$ & & $\begin{array}{l}\text { Soil screening and sugar flotation, emer- } \\
\text { gence traps }\end{array}$ & $\begin{array}{l}\text { Sampling strategy; handling and } \\
\text { processing }\end{array}$ \\
\hline
\end{tabular}

Although sand flies are principally found in the warmer parts of the world including southern Europe, Asia, Africa, Australia and South America, their distribution extends northwards to just above latitude $50^{\circ} \mathrm{N}$ in southwest Canada, northern France and Mongolia. Their southernmost distribution is at about latitude $40^{\circ} \mathrm{S}$, but they are absent from New Zealand and the Pacific islands. Their altitudinal distribution is from below sea level (by the Dead Sea) to $3500 \mathrm{~m}$ above sea level in Afghanistan (Phlebotomus rupester) (Artemiev, 1980; Lane, 1993; Killick-Kendrick, 1999). Sand flies are generally associated with desert and semi-arid ecosystems in the Old World and forests in the New World. They breed in a wide variety of habitats in domestic, peridomestic and sylvatic environments, including abandoned buildings, cracks in floors and walls, animal burrows, domestic animal shelters, garbage, under stones, soil, caves, termite mounds, tree roots and leaf litter, among others (Feliciangeli, 2004).

According to literature, among the species resident in Europe, ten are medically important, namely Phlebotomus (Larroussius) ariasi, Phlebotomus (Larroussius) perniciosus, Phlebotomus (Larroussius) perfiliewi, Phlebotomus (Larroussius) major s.l., Phlebotomus (Larroussius) tobbi, Phlebotomus (Phlebotomus) papatasi, Phlebotomus (Paraphlebotomus) sergenti, Phlebotomus (Paraphlebotomus) similis and Phlebotomus (Paraphlebotomus) alexandri. Most of them are proven vectors of leishmaniasis and several phleboviruses. Although the vectorial role of Phlebotomus (Transphlebotomus) mascittii has not been confirmed, correlation between its distribution and the autochthonous cases of leishmaniasis in some parts of Europe has led to research on its biology and distribution. Additional information on the distribution of these species in Europe is updated on the ECDC website VBORNET project: http://ecdc.europa.eu/en/activities/diseaseprogrammes / emerging_and_vector_borne_diseases/Pages/VBORNET_maps sandflies.aspx, and the VBORNET Project web site: http:// www.vbornet.eu

Studies of sand fly-pathogen relationships and vector behaviour, taxonomy or ecology require sampling methods that maintain the insects alive or in an adequate state of preservation for transportation to the laboratory and processing. This review prepared by ECDC-VBORNET PROJECT provides a critical guide to sampling methods used for sand flies. The review covers the collection and interpretation of field data, describes suitable techniques for the preservation of specimens obtained by each method of collection, provides advice on how to conduct surveys, indicates molecular techniques used in identification of species and discusses pathogens associated with sand flies and their detection methods. Advantages and disadvantages of each type of method are also considered with regard to practicality, safety and cost.

It is important to be aware that each method has its own limitation in relation to environmental factors and the vector's natural or induced behaviour. As adequate sampling and processing of material are essential for obtaining significant information, the epidemiologist, entomologist and/or researcher should agree together the extent of the entomological investigations to be undertaken in each situation in order to achieve the study objectives (Table 1), with adjustments made to meet local requirements.

\section{Sampling methods of adult sand flies}

Vector surveillance aims to detect the presence of a vector in a given population or to determine vector abundance for estimating the risk of disease transmission, and hence the sampling methods required will depend upon the questions to be addressed. Sampling methods exist for both the adult and the immature stages of sand flies (Table 2). The most used trapping methods are light traps for host-seeking females and sticky traps or aspirator collection for the resting population, although depending upon the specific research objective, a range of other traps and techniques are available and may be used in the field.

\section{Light traps}

Light traps are used extensively in field studies on sand flies. The most widely used trap is a battery-operated lightsuction trap, with the main advantage being that it can be left overnight to collect sand flies (fig. 1, Table 2). The New Jersey Mosquito Light Trap, first developed in 1932, has been the most widely used light trap for sand fly work. The trap operates by sucking sand flies into a funnel with a mesh screen adapted to the size of the sand flies, terminating in a killing bottle. For special investigations in which live caught sand flies are required, the killing bottle is replaced by a holding cage, which can be changed several times during the same night, as required. Although the range over which this trap attracts sand flies is not large, it is highly efficient if located among resting or breeding places and if the right light source is used (Table 3). Light traps attract host-seeking sand flies, but 
Table 2. Overview of the sand fly trapping methods indicating advantages and limitations.

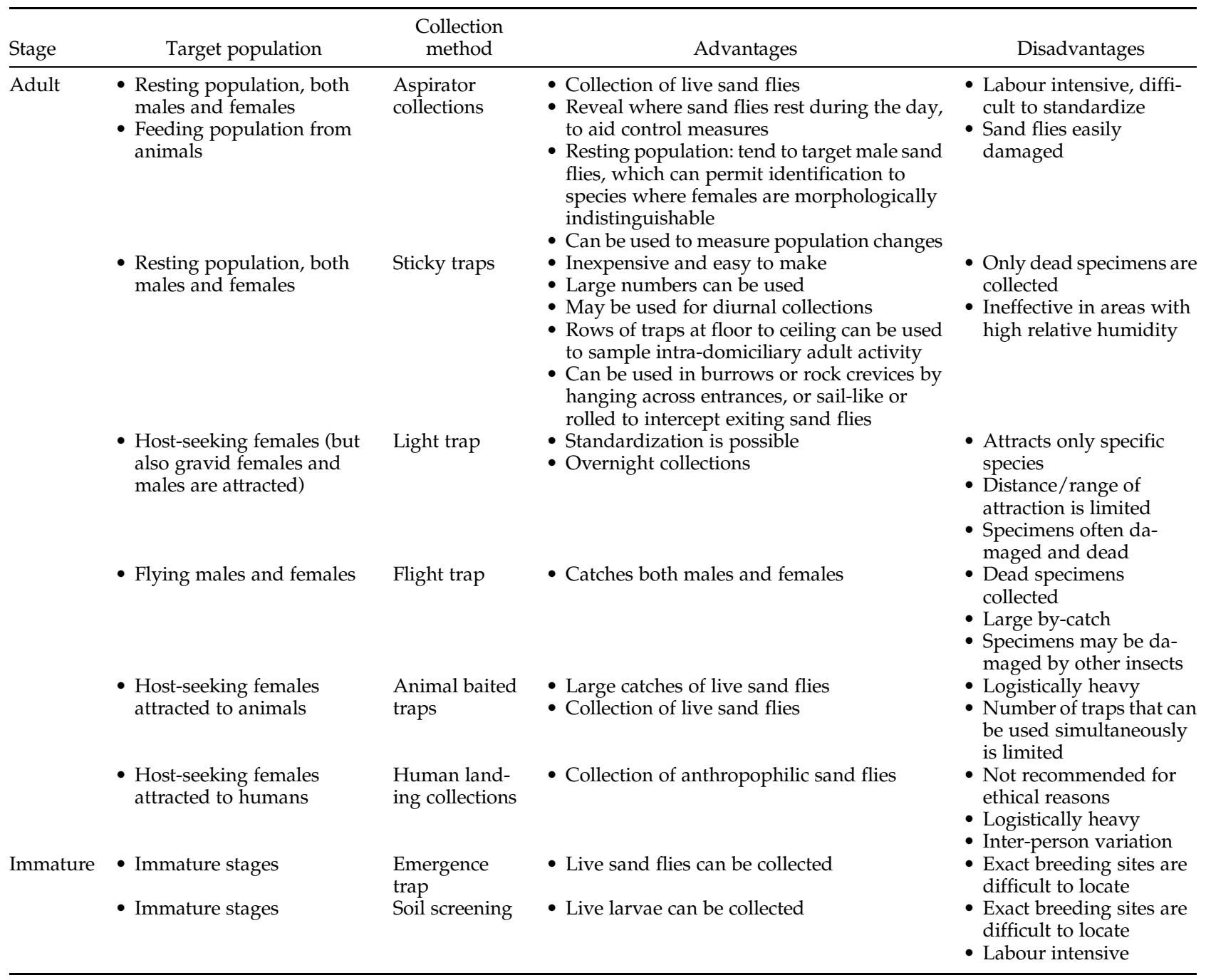

also yield gravid females and males. A potential disadvantage of light traps is that they preferentially sample females of some groups (such as Lutzomyia subgenus Psychodopygus) that are highly phototropic and do not attract some other groups or species such as Sergentomyia minuta in southern France. Although they are useful in catching large numbers of certain species and measuring relative changes in abundance of these species over time and space, light traps have somehow limited value in ecological studies of sand flies. Some species may be relatively more active at greater heights above the ground, even at tree canopy height, and therefore tend to be underrepresented in samples taken at ground level. Care must be taken in interpreting results of vertical distribution studies based on light trapping, as sand flies may fly upwards in response to the unusual light source, because these movements constitute part of their normal behaviour.

\section{Sticky traps}

Sticky traps constitute a method of sampling sand flies by interception rather than attraction. Standardized pieces of white un-waxed paper or cards are soaked in castor oil and placed in sand fly resting places overnight (at least two or three consecutive days) (fig. 2, Table 3). To obtain quantitative results, either one or both sides of the paper must be completely exposed. The number of papers used at each sampling event is normally constant. These traps are generally inexpensive and easy to manufacture in large numbers. They can be prepared in bulk before field studies and stored until required (Table 3). Because of the viscosity of castor oil they are ineffective in habitats with high relative humidity and only dead specimens are collected.

\section{Flight traps}

Malaise traps are designed to catch flying insects, and consist of a tent-like nylon structure hung across trees or bushes in likely insect flight paths. Insects entering the trap are directed by the sloped roof into two transparent plastic or glass cylinders at either end of the structure, which contain a killing agent such as ethyl acetate, carbon tetrachloride or potassium cyanate in a plaster of Paris vial. Modifications can be made to 


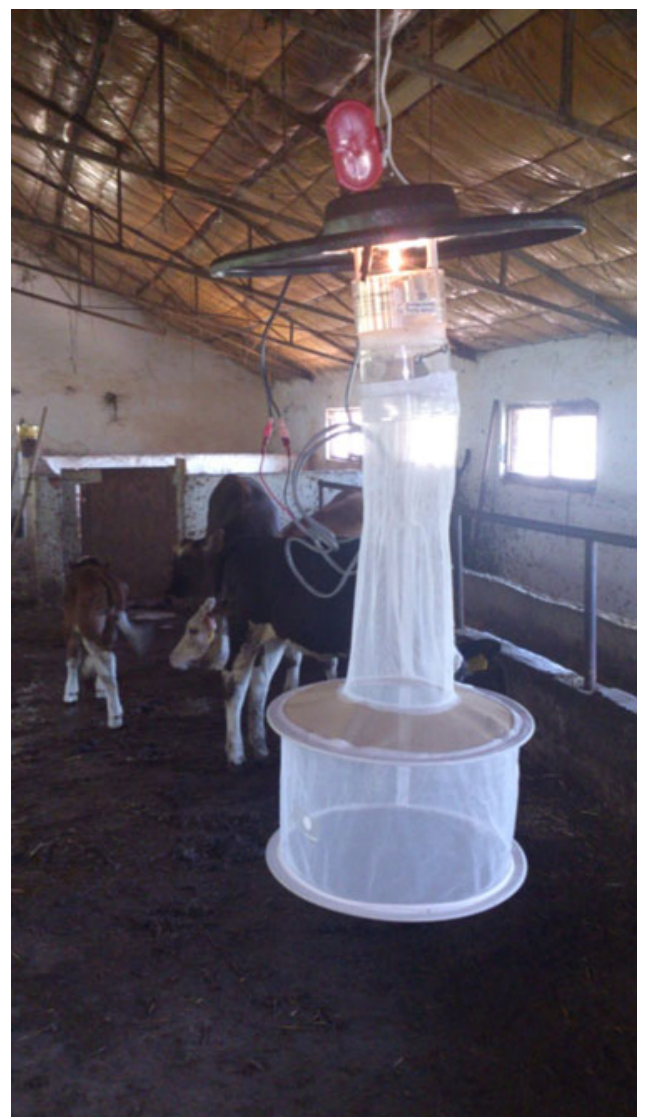

Fig. 1. Light trapping for sand flies in Turkey (Photo credit: Filiz Gunay \& Gizem Oguz).

the entrance of the cylinders, e.g., reducing the opening size or fitting a wire mesh, to prevent the entry of larger flying insects, which may damage or eat fragile sand flies. Malaise traps can be assembled from everyday materials (Gressitt \& Gressitt, 1962; Townes, 1962). Sand flies are likely to be trapped in small numbers, but an advantage is that both male and females will be caught, required for the identification of some species (Alexander, 2000). In addition, this method allows the detection of all sand fly species present within a habitat, while reducing sampling bias.

\section{Aspirator collections}

Sand flies can be collected by an aspirator from animals, and when resting on walls in buildings or animal shelters, with the main advantage of collecting live specimens. Sand flies are fragile and therefore the body of the aspirator should be wider than the opening. Plastic aspirators are light and strong but can damage sand flies because of static electricity. Therefore, a glass aspirator is recommended for most studies both in the field and in the laboratory. However, they are not commercially available. The Castro aspirator, a modification of the mouth aspirator, is made from a length of rubber tubing attached to the glass/plastic tube, with fine mesh gauze sealing the connection between the two components (Alexander, 2000). This allows sand flies to be sucked up rapidly and then quickly blown into holding containers, the principal advantage being that insects collected from different microhabitats during a single session can be separated to provide more data, rather than being stored together in a single aspirator. Additionally, the Castro aspirator can be cleared regularly so that hairs shed by sand flies inside the tube are not inhaled by the operator. Holding containers can be made from $100 \mathrm{ml}$ urine cups: plaster of Paris is applied to the base, a circle is cut from the lid and covered with gauze, and another hole is cut into the container's side then covered with two pieces of rubber, one slit vertically and the other horizontally, to produce a seal with a cross-like opening through which the aspirator tube can be inserted to blow collected sand flies inside. When working with a large number of sand flies, a reservoir type is favoured, with the body wider than the entrance. It consists of a tube sealed at one end by rubber, except for a narrow tube through which the sand flies enter. This makes it difficult for the insects to escape and helps to capture more specimens without the necessity to transfer them into a cage or other type of container. Emptying the reservoir aspirator may involve dismantling it within a cage. Hand-held poweroperated aspirators are also available and these should be used in the field for sand fly collections from crevices, stables, or even from traps. Sand flies are easily captured in the periphery of direct light.

\section{Animal baited traps}

If the objective of the study is to detect the presence and the relative density of sand flies biting animals in a given area and/or to collect material (both females and males) for observation, animal-baited traps are the most appropriate tools. They are also useful for host preference studies. The bed net trap consists of a large mosquito net with smaller mesh size (200 meshes per square inch) for sand flies suspended from four poles, with a second smaller net inside under which the bait animal is placed. The amount of free space should be determined by experience with local sand fly species. The trap net should be made as tight and as rigid as possible, the edge of the net being tied with string and pegged into the ground. This prevents the net from flapping in the wind, which deters and disturbs the sand flies. Animal-baited traps have also been used for indoor collections.

Many kinds of animal-baited traps have been used in the field such as the Disney trap, the cone trap and animal-baited box trap, each with advantages or disadvantages depending on the aim of the study. A range of animals have been used as bait including cattle, donkeys, small mammals, chickens, ducks and dogs. To prepare the Disney trap, a cage containing an animal is placed in the centre of a metal tray, which is then coated in castor oil, and the apparatus is covered by a plastic/ canvas roof to protect it from the rain (Disney, 1996). Female sand flies approaching the bait animal are trapped in the sticky oil, due to the fact that sand flies tend to land near to their host and approach in a few short hops rather than landing directly on the host. Blood-fed females that avoided the oil on their way to the animal may also be trapped after feeding. As with sticky traps, only dead specimens are collected. The cone trap consists of a large tent of semi-transparent material arranged over the bait, usually a large animal such as a horse or donkey (Montoya-Lerma \& Lane, 1996). The material used allows the sand flies to sense the animal by sight, but also via other stimuli: $\mathrm{CO}_{2}$, body heat and odour (Alexander, 2000). Blood-seeking sand flies enter the trap through funnels ending in small apertures, making escape difficult, and can be 
Table 3. Overview of technical and operational requirements of two sand fly collection methods.

LIGHT TRAP - fig. 1

Technical requirements

- It is possible to adapt and/or modify light traps for mosquitoes. In the case of the CDC miniature light trap, it is possible to change from the larger mesh size of funnel used for mosquitoes, to a smaller mesh size type (preferentially 150-200 meshes per square inch).

- The distance at which these traps are attractive to sand flies appears to be limited. Killick-Kendrick et al. (1985) concluded that $P$. ariasi was attracted to CDC light traps from a maximum distance of only two metres. Valenta et al. (1995) determined that the maximum range of attraction to a $60 \mathrm{~W}$ light bulb for Lutzomyia youngi was $6 \mathrm{~m}$. This information is important when considering efficient collections in the field. Light traps require the correct light source. Latest generation light traps generally require the following bulb types (recommended by several studies): (1) Type CM-47; voltage 6.3; $\mathrm{mA} \mathrm{h}^{-1} 150$; Candlepower 0.52; Lifespan (h) 3000; (2)Type CM-44; voltage 6.3; $\mathrm{mA} \mathrm{h}^{-1}$ 250; Candlepower 0.90; Lifespan (h) 3000.

- Light traps also require ca. $320 \mathrm{~mA}(0.320 \mathrm{~A})$ per hour to operate at 6.0-6.3 V DC. Four D-size flashlight batteries (preferably alkaline) in series will provide power for one night's operation. However, motor cycle, lead-acid, $6 \mathrm{~V}$ batteries provide many nights worth of power on one charge, and these are the most common power source. A $6 \mathrm{~V}$ battery capacity of $10 \mathrm{AH}$ is a good size for these traps. Although a light source can be efficient, an additional lure is often required. All of which can be used with light traps.

Operational - Traps should be placed before dusk and emptied in the morning (after dawn). Collections should be rapidly rerequirements moved from the trap to limit damage from heat and/or desiccation.

- Traps should be suspended 1.5-2 m above the ground, preferably at least $10 \mathrm{~m}$ or more from an external light source. Background light intensity negatively affects the efficiency of trapping capacity of light traps. Hence, it is better to avoid areas near other sources of artificial light, as well as sites exposed to strong winds, places near buildings housing animals, or those areas exposed to industrial fumes and smoke.

- A single trap usually reflects sand fly flight activity within a few metres of its location. A sufficient number of traps must be utilized to ensure a representative sample. If a site fails to produce the expected number of sand flies, judging from collections in other traps in the area, the trap should be relocated. Sometimes a shift of only a few metres makes a considerable difference in the number of sand flies attracted.

- The sand fly catch can be augmented by an additional source of carbon dioxide $\left(\mathrm{CO}_{2}\right)$, such as dry ice (approximately $700 \mathrm{~g}$ per night). According to Service (1993), mosquito response to $\mathrm{CO}_{2}$ becomes saturated at levels close to that of human exhaled breath $(4.5 \%)$ and gas released from a trap would therefore remain above the background atmospheric level $(0.03 \%)$ until dispersed downwind and diluted by a factor of 100 . Therefore, $\mathrm{CO}_{2}$ is usually a long-range attractant for sand flies as for mosquitoes, whereas light is probably perceived by sand flies at much closer range. The addition of a source of $\mathrm{CO}_{2}$ can therefore improve catches by increasing the effective range of the sampling area of a light trap (Veronesi et al., 2007; Erisoz Kasap et al., 2009; Kline et al., 2011). Depending on the species, adding olfactory attractants (such as octenol), replacing incandescent bulbs with a long wave ultraviolet light source or inverting the light traps were found to increase the collection size (Faiman et al., 2009; Kline et al., 2011).

STICKY TRAPS - fig. 2 Technical requirements

- There is no commercially available standard template form. Many studies suggest the use of $20 \times 20 \mathrm{~cm}$ or $25 \times 20 \mathrm{~cm}$ standard papers, but it is not obligatory, so A4 plain paper can be used. The catch results by sticky traps are expressed as 'number of sand flies per $\mathrm{m}^{2}$ of sticky paper per night'. The formula is: total number of collected specimens/total surface of sticky traps used $\left(\mathrm{m}^{2}\right)$ (if both sides of the sticky paper are exposed, both have to be considered in the surface calculation formula).

- Preparation of oil-impregnated papers is simple: papers (different sizes mentioned above) are dipped into a sufficient amount of castor oil in a plastic container (uptake rate of $20 \times 20 \mathrm{~cm}$ paper: 11 oil / at least 250 papers). Using plastic gloves vigorously move the papers in the oil. When the papers take up no further oil, they are removed from the container and allowed to drip dry, and then placed in plastic bags. It is possible to apply oil using a paint roller to both sides; however these strategies can be time consuming. Alternatively, prepared papers can be placed in a lockable plastic container with an appropriate amount of castor oil. In the field, oil-coated papers can be removed and used as required.

- If sticky traps are intended to be left exposed to the sun during very hot days, high viscosity oils such as castor oil are suggested. Castor oil-impregnated sticky traps can be used productively in dry areas such as desert and dry mountain valleys, even though they are also effective to collect sand fly adults in habitats with different conditions. Sand flies are removed from the oiled paper (e.g., with a small brush) washed in saline or a drop of alcohol $(70 \%)$ and then identified. Only dead specimens can be collected with these traps.

Operational requirements
- The papers are fixed in the proximity of resting places with tools (e.g., wooden or bamboo support, wire, hook, staple or paper clip) according to the shape of the resting place or applied directly onto the wall.

- Sticky traps can be located around resting places in large numbers. Possible resting sites include animal barns (inside/outside), houses (inside/outside), poultry houses (inside/outside), caves, tree holes, leaf litter, between or under rocks and animal burrows, rock crevices, holes of walls and among vegetation. Rows of traps hung at floor level, $20-50 \mathrm{~cm}$ above the ground or ceiling level can be used in, for example, animal barns or houses. Animal burrows and rock crevices are used as diurnal resting or breeding sites by many species and sticky traps hung across the entrances. For instance, in Mediterranean France, wall holes (barbacanes) near roads or in villages are very important resting places for $P$. ariasi so that, mounted sail-like on small sticks or rolled, sticky traps can be used to collect sand fly specimens in the holes. For these types of resting places, a good place to locate traps is in the vicinity of a hole with a thin layer of moist soil and vegetation, as these can be good resting sites.

- More information on different methods on how to use sticky papers efficiently or where to place them during field studies are described in Alexander (2000). 

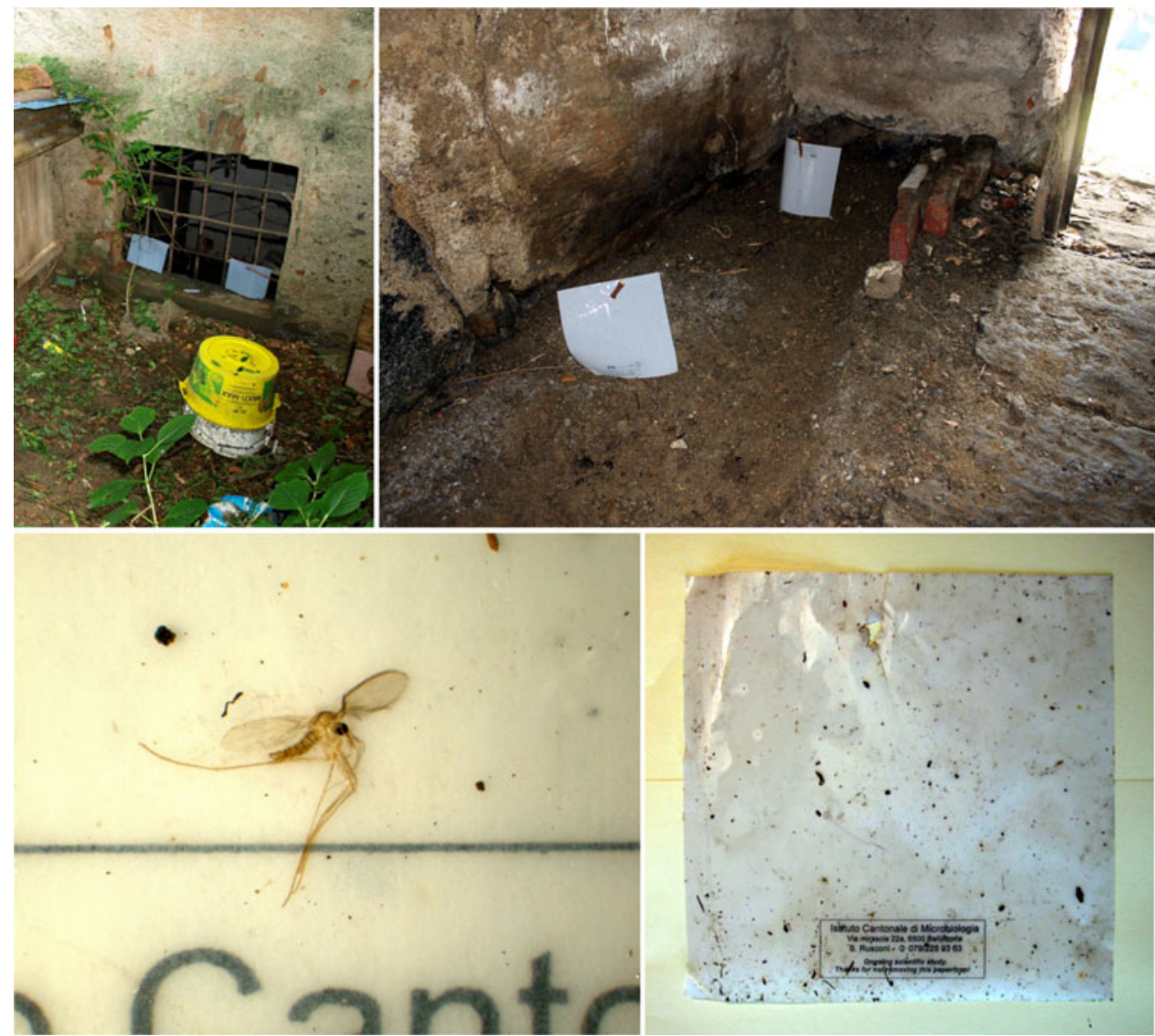

Fig. 2. Sticky traps used in Switzerland (Photo credit: Francis Schaffner).

collected from inside the trap by aspiration at the end of the trapping period. The animal-baited box trap (Espinola et al., 1983) comprises a wooden box divided into two chambers which are connected by hinges and separated by a mesh screen. The large bottom chamber holds the bait animal while the upper chamber collects sand flies which are attracted to the animal and enter through two funnels in the box's lid.

\section{Human landing catches}

Catching host-seeking flies landing on people they intend to bite, the so-called 'human landing collections', are the most productive method of collecting anthropophilic Diptera. Because of the danger of contracting leishmaniasis and other infections, the flies should not be allowed to actually bite. For ethical reasons, 'human biting collections' are officially discouraged or prohibited by many funding agencies. It is recommended that human landing catches be performed for pre-determined periods of time so that data are comparable (e.g., no. flies per man-hour), and so that risk to collectors is reduced.

Maroli et al. (1997) describe a bed net trap (mentioned above) in which a human volunteer lying on a bed and protected by fine-mesh mosquito net is enclosed within a second net, elevated a few centimetres above the ground to permit access of sand flies attracted to the human bait. The insects that enter have a tendency to move towards the upper limits of this second net, from where they can be aspirated at the end of the observation period.

\section{Sampling methods of immature sand flies}

Sand flies oviposit in terrestrial microhabitats where their developmental stages are seldom found. For this reason control measures directed against immature stages are not considered as an option in leishmaniasis control programmes. There are two main approaches to look for breeding sites. One involves placing emergence traps in places where adult insects have been found resting (Table 2). These are inspected at regular intervals and newly emerged adults are collected. Depending on the type of microhabitats, different kinds of emergence traps can be used (Moncaz et al., 2012). Empty pupal cases at the soil-air interface and resting adult male flies with their genitalia in the teneral position (at $180^{\circ}$ to that of the mature specimens) are indications of a breeding site. The second approach to finding immature phlebotomines involves a variation of the sugar flotation technique (McCombie-Young et al., 1926; Hanson, 1961; Thatcher, 1968; Rutledge \& Mosser, 1972). Soil and leaf litter samples from potential breeding sites are mixed with water and the supernatant (containing material such as dead leaves and exuviae of insects) is poured off. The remaining material is mixed with a saturated sugar solution and sand fly larvae float to the surface, from which they are collected and placed in 

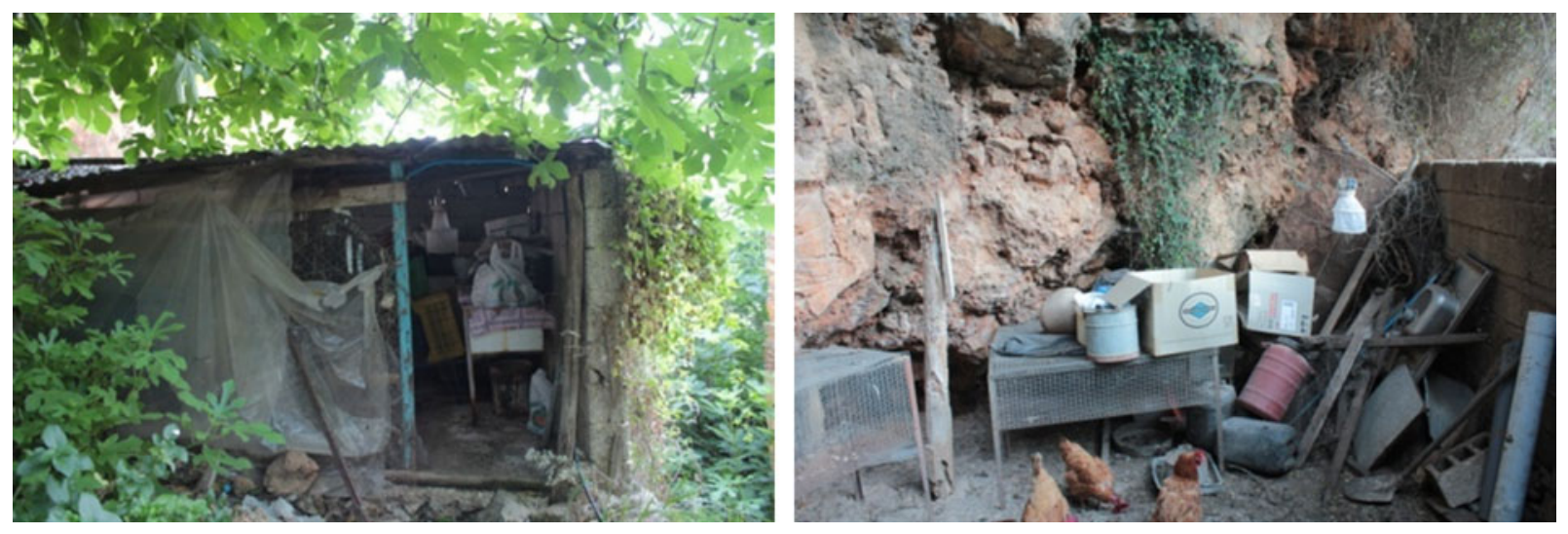

Fig. 3. P. similis habitat in Crete (Photo credit: Maria Antoniou).

plaster-lined pots containing some suitable larval diet. This method has the advantage of preserving the larvae alive so that they can be reared to adults, this being of critical importance in areas where more than one sand fly species occurs, because specific identification of immature stages is generally impossible.

\section{Sampling strategy}

Several factors affect the success of sampling methods. In the European region of the Old World sand fly activity is limited to the summer months. By contrast, New World leishmaniases have a distribution that is almost exclusively tropical. Precipitation rather than temperature is the principal climatic factor that determines the sand fly seasons (Alexander, 2000). Decreases in the populations of anthropophilic species are preceded by corresponding peaks in rainfall, which also reduces the amount of suitable diurnal resting sites for the adult insects, as well as limiting adult flight activity. Hence, the timing of the survey programme is dependent on climatic, ecological and the geographical situation of the study site. For example, the active sampling period of sand fly species in southern Europe is between April and late October. Moreover, different sand fly species have different seasonal activity periods and different peaks of activity. It is possible however, using various sampling methods, to collect a number of species together during field visits; however the number of specimens per species will be variable. Ideally, a variety of different sampling methods should be employed during each survey, as particular methods may favour a single sand fly species, which may not be the most abundant or important from a public health perspective.

There are a number of health and safety risks that should be noted when sampling in sand fly habitats. Firstly, phlebotomines often share microhabitats with dangerous animals, such as scorpions and snakes. Secondly, there is a potential risk of acquiring respiratory infections such as histoplasmosis from aspirating in humid environments where sand flies rest (Alexander, 2000). Also, the inhalation of sand fly hairs during aspiration may cause respiratory irritation.

\section{Trapping density and frequency}

The trapping density and frequency are dependent on several factors such as the study objectives, capacity of the team and finances. First the researchers have to make a decision on the number of samples per habitat unit. Aspects to consider include: (a) whether different regions of the unit need to be sampled separately, for instance according to altitude, vegetation, or microhabitats and (b) the number of samples within each unit/subunit for maximum efficiency. The distribution of the population throughout the habitat can be biased towards certain subdivisions. It is sometimes important that if the distribution of the population throughout the habitat is biased towards certain subdivisions but the samples are taken randomly, 'systematic errors' will arise. This can be overcome either by sampling so that the differential number of samples from each subdivision reproduces the gradient in the habitat or by regarding each part separately and subsequently correcting. To select the sampling unit and its size and shape it is important to decide the trapping density and frequency. The criteria for the sample unit must: (a) have an equal chance of selection by sampling, (b) have stability (or, if not, the changes should be easily and continuously measured) by regarding, (c) lend itself to conversion to unit areas, (d) be easily delineated in the field, (e) be of such a size as to provide a reasonable balance between the variance and the cost, (f) not be too small in relation to the species' population size, as this would increase edge-effect errors. The objectives of the study will also determine the sampling pattern. If the aim is to obtain estimates of the mean density then variance should be minimized. It is preferable that both the trapping density and trapping frequency are high. Trapping twice a month with a sufficient amount of traps (for sticky traps it is unlimited because of their very low cost and ease of preparation; for CDC light traps, the unit is $10-15$ traps per $500 \mathrm{~m}$ ) is required to keep variance errors at a minimum level.

Generally, light traps are operated on a regular basis of 1-7 nights/week; with four nights giving as valid an index as 7 nights/week. Therefore, trap collections should be made on four consecutive nights, such as Monday through Thursday of each week. For more information refer to Southwood \& Henderson (2000).

Different sand fly species breed and rest in different habitats (figs 3-7), prefer urban and/or rural areas, sheltered and/ or open areas. For instance, $S$. minuta prefers spaces between small rocks, while $P$. mascittii prefers caves as resting sites. In general, adult sand flies shelter during the day in dark locations in various resting sites, humid places such as tree-holes, or arid places such as under rocks, or animal burrows, barns, 

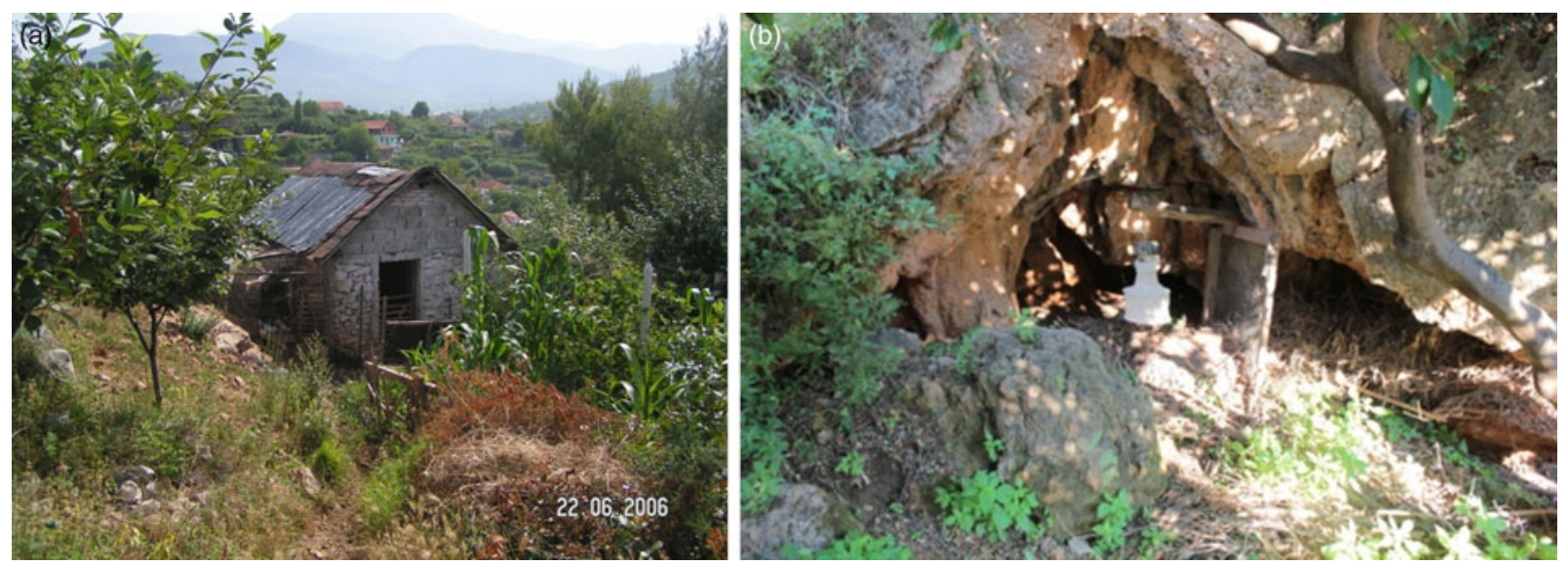

Fig. 4. P. neglectus habitat in (a) Albania (Photo credit: Enkelejda Velo) and (b) Crete (Photo credit: Maria Antoniou).
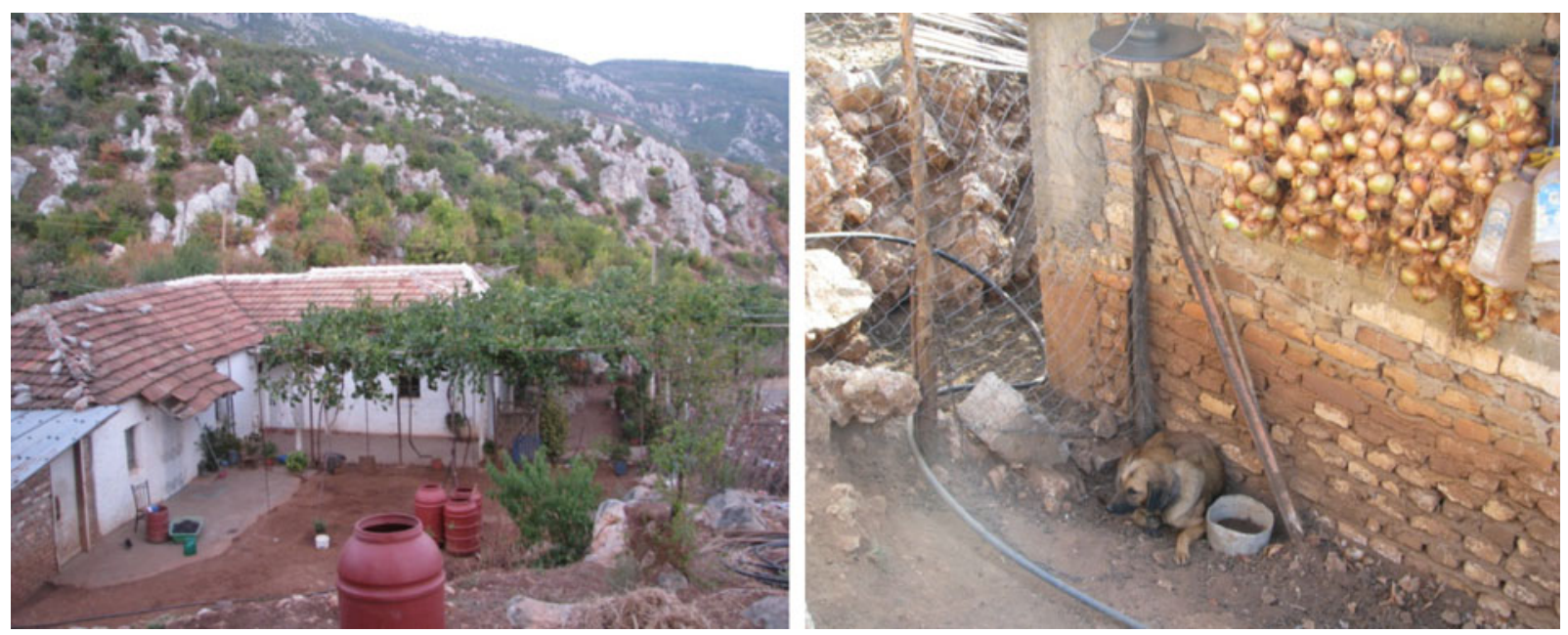

Fig. 5. P. tobbi habitat in Albania (Photo credit: Enkelejda Velo).
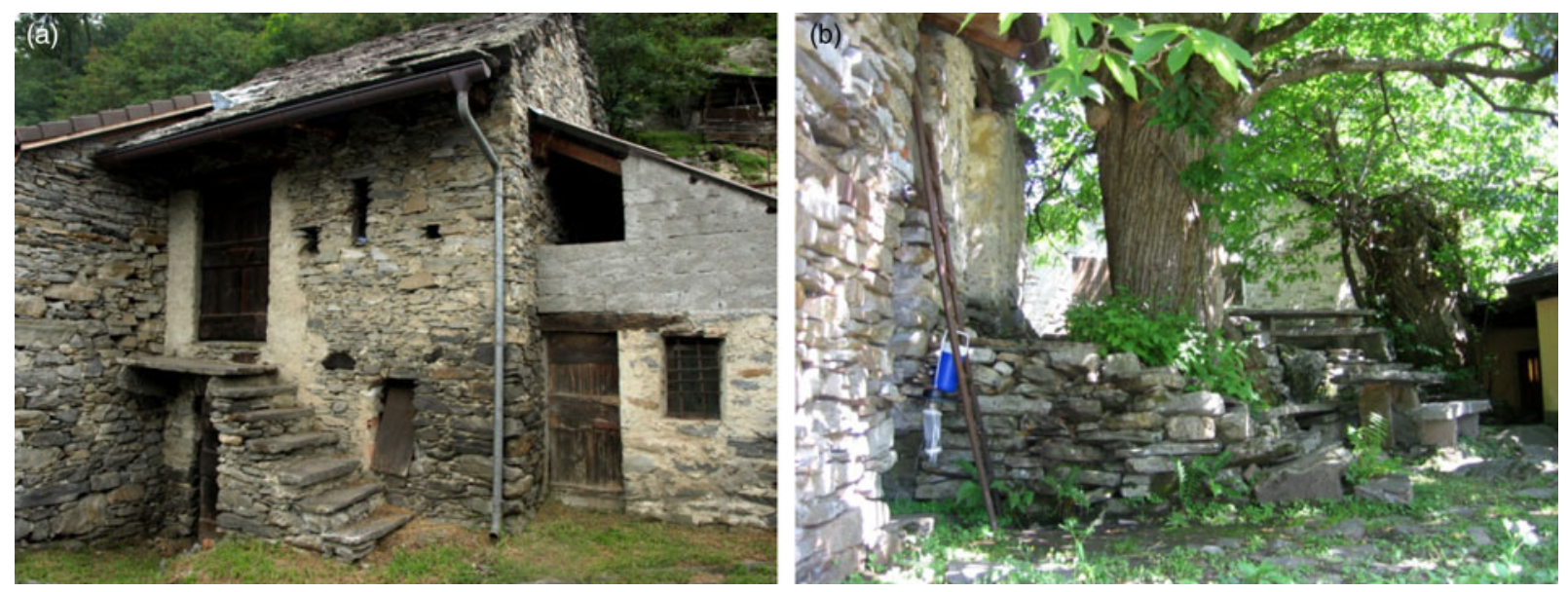

Fig. 6. P. perniciosus habitat (a) in Ticino, Switzerland, (b) $\mathrm{CO}_{2}$-baited light trap (Photo credit: Francis Schaffner). 

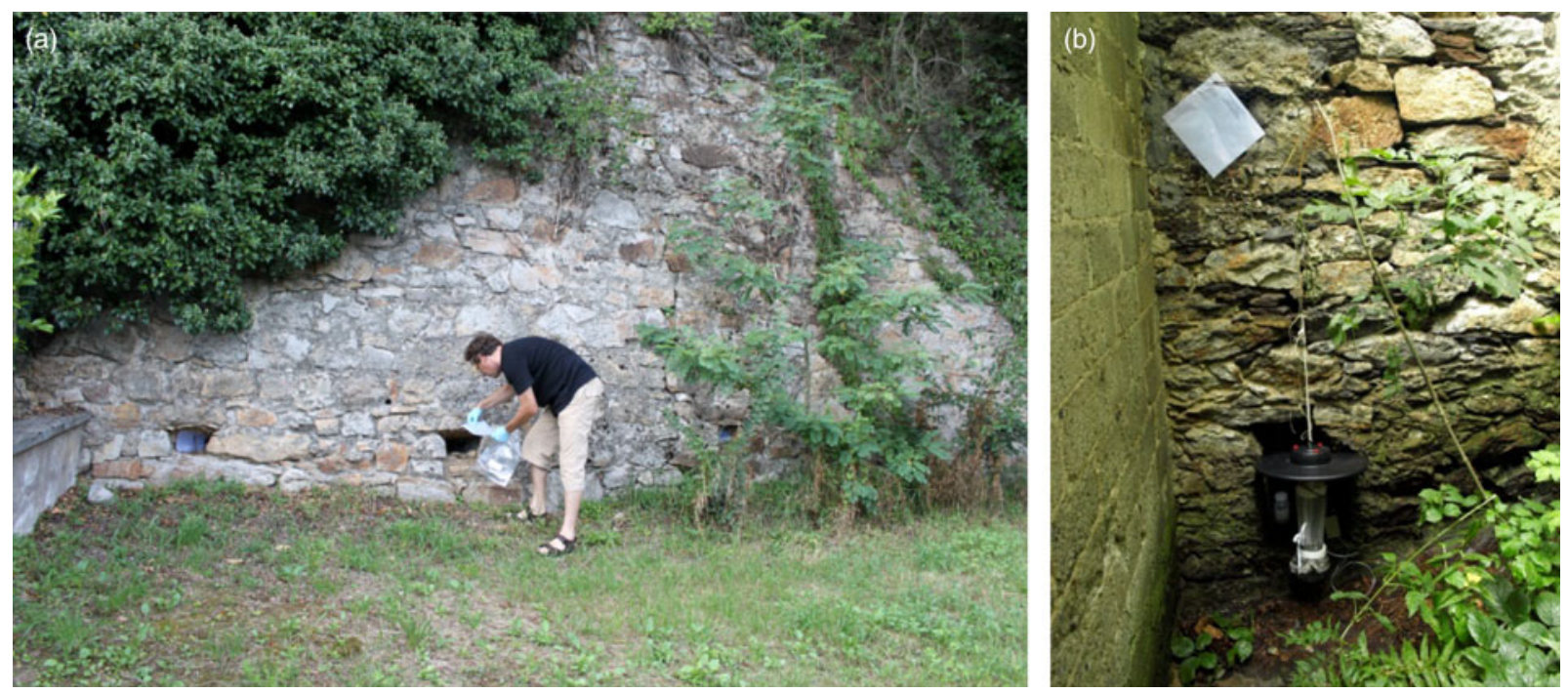

Fig. 7 P. mascittii habitat in (a) Alsace, France and (b) Ticino, Switzerland; combination of light and sticky traps (Photo credit: Francis Schaffner).

inside houses or under leaves. Resting site collections may be the best method for obtaining male sand flies, which are required for the identification of some species. Generally there are no differences between trapping techniques but some modification according to resting place may be needed.

Local people may be able to provide useful information to researchers, which may be important in identifying areas of sand fly abundance, seasonal activity, etc. and could help direct sampling efforts. If sand flies are perceived locally as a public health problem, people living in the area are likely to engage with any control measures that are implemented in the future, and may even assist with sampling activities.

\section{Factors influencing the collections}

Sand flies are small, fragile, nocturnally active insects with weak direct flight capability. Several factors may affect the success of sampling methods. Sand fly flight activity is limited by rain, wind or low temperatures and attraction to bait animals depends on the direction in which the odour plume is wafted. Moonlight reduces the distance at which CDC light trap illumination equals background levels and thus the effective sampling area and the number of sand flies are likely to be caught. There is considerable difference in light intensity between moonless nights and those with a full moon; Kuiper (1938) calculated a 140-fold difference in radiation between the two extremes. Bowden \& Morris (1975) expressed the relationship as 'catch constant $\times(\mathrm{W} / \mathrm{I})^{\prime}$ ' where $\mathrm{W}$ is the trap illumination and I is background light intensity. Although strong moonlight may interfere with light trap collections, it is sometimes associated with increased activity in mosquito populations, and may be similar for sand flies. Nevertheless, the relationship between moonlight or the lunar cycle and the abundance and activity of sand flies has been controversial (Santos-De Marco et al., 2002).

Several types of trap such as sticky traps and flight interception traps catch insects that are carried into or onto them by the wind; consequently their practical use varies with wind speed. Other variables noted by Martin et al. (1994) as influencing sticky trap sampling efficiency for three species of black fly, were wind speed, light, temperature, saturation deficit and time of day. A similar list would be found for sand flies. In general, adult sand flies do not fly in wind of more than $2-3 \mathrm{~m} \mathrm{~s}^{-1}$.

For the reasons discussed above, researchers measure the variation of climatic conditions such as temperature, relative humidity and wind speed throughout the field study or representative area(s) of the study area with sensitive devices such as data-loggers or portable climate stations. The measurement of climatic factors is meaningful when you measure for the entire area. The data obtained from these measurements allow comparisons between population fluctuations and climatic factors that may affect sand fly abundance.

Sand flies are highly susceptible to contact insecticides and spraying programmes directed against mosquitoes or agricultural pests, which are likely to reduce phlebotomine activity in the same habitats.

\section{Handling and processing sampled sand flies}

The preservation technique used for transportation of sand flies depends on the purpose for which the specimens were obtained. Those to be used in taxonomic studies can be preserved dry in layers of tissue paper prior to being cleared in lactophenol for identification and subsequent slide mounting in Canada balsam, Berlese, or Eupharal fluids (Moore \& Gage, 1996; Alexander, 2000; Marquardt et al., 2005; Volf \& Volfova, 2011). Storage in $70 \%$ alcohol can improve the chances of specimens remaining intact but complicates the clearing process by hardening the muscles of the insects and obscuring internal structures such as the female spermathecae used in identification. Uncleared specimens should not be kept in alcohol for more than 6 months. The best way to transport adult specimens to the laboratory for identification or establishment of a colony is to keep them alive with larval pots which have a layer of plaster of Paris on the sides and bottom and closed with a snap cap top and fine gauze, placed into a plastic ice-container at $4^{\circ} \mathrm{C}$. 

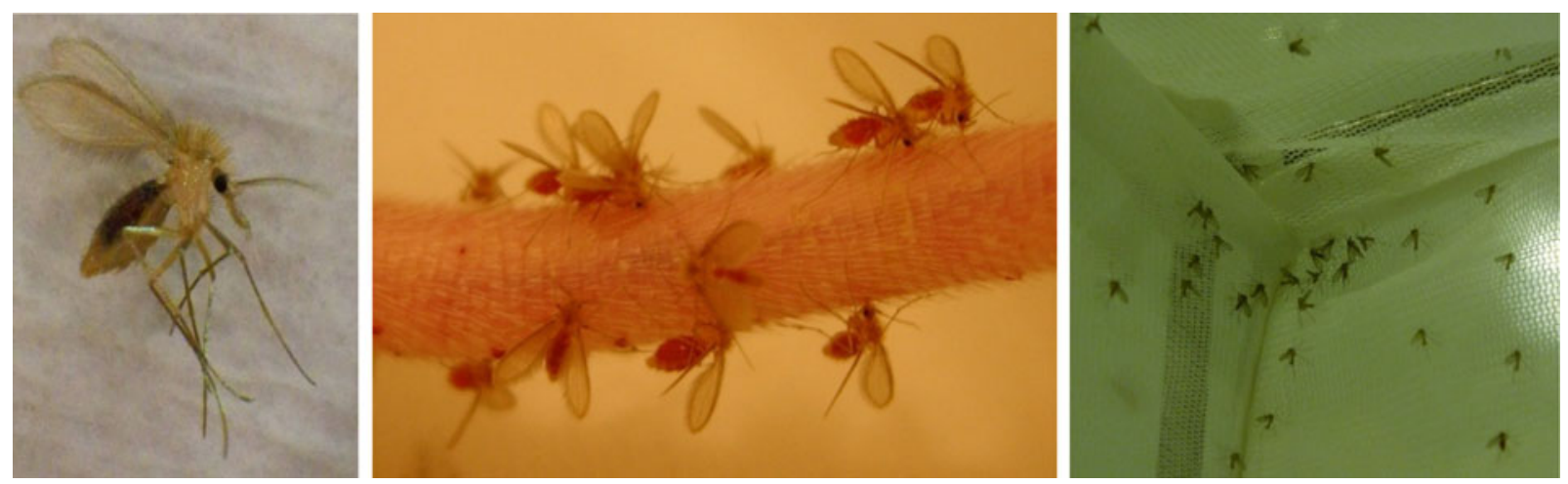

Fig. 8. Specimen preservation and laboratory rearing of P. papatasi (Photo credit: Filiz Gunay \& Gizem Oguz).

The presence of sympatric, morphologically identical species in a particular habitat can be detected using a variety of sampling methods and regimes to reveal differences in activity and other behavioural aspects. These observations can subsequently be confirmed by techniques such as isoenzyme electrophoresis or DNA studies.

Because enzymes used in studies of population genetics must retain their activity after electrophoresis, sand flies must be kept alive (fig. 8) until processed in the laboratory or stored at temperatures below $-40^{\circ} \mathrm{C}$, for example, at $-80^{\circ}$ $\mathrm{C}$ or in liquid nitrogen. Specimens to be examined for natural Leishmania infections should be immobilized and immersed in a detergent solution to dissolve the oil on the water-repellent hairs that cover their bodies and ensure that the insects do not remain floating on the surface of the solution in which they are to be preserved. This should contain a cryoprotectant such as $10 \%$ dimethyl sulphoxide in phosphate-buffered saline. The vials containing the insects are submitted to a 30 min cooling period in a styrofoam container placed in the neck of a liquid nitrogen tank or dry shipper prior to total immersion. Yaghoobi-Ershadi \& Javadin (1996), working in Iran, were able to recover natural infections of sand flies captured on sticky traps in rodent burrows and retrieved the next morning. According to Moore \& Gage (1996) however, sticky traps are unlikely to produce specimens suitable for virus isolation because the oil used on the surface of traps interferes with cell culture.

Studies involving DNA-based protocols can use dried, fresh, frozen or alcohol-preserved specimens whereas those for pheromone analysis should be placed fresh in a Pasteur pipette or glass tube containing hexane and heat-sealed. Insects intended for establishment of colonies, behavioural studies or immediate dissection on return to the laboratory should be transported alive in larval pots placed inside styrofoam boxes supplied with a damp sponge or cloth and a sugar source such as an apple slice or cotton wool pad saturated in sucrose solution.

For virology studies, collected sand fly adults must be transported to the laboratory on dry ice, or alive into larval pots mentioned above. If adults are transported alive to the laboratory, they should be placed and killed in a freezer $\left(-80^{\circ} \mathrm{C}\right)$ immediately. This process will preserve the virus RNA.

Although several age-grading methods have been developed for bloodsucking insects, probably the only fairly reliable technique for sand flies involves the examination of the ovarioles for follicular dilations to determine the number of gonotrophic cycles females have undergone (Detinova, 1962). This requires that the insects be kept alive or preserved in liquid nitrogen with a cryoprotectant until they can be transported to the laboratory and dissected. Anez \& Tang (1997), however, claimed that sand fly ovaries were unsuitable for the application of these techniques because they show no obvious and reliable changes in tracheolar coiling or follicular dilatations that can be correlated with parity.

For the detailed microscopic examination of external or internal structures, sand flies may be preserved on slides in mounting media, of which the following are recommended: chloralhydrate medium gelatin, lactophenol, Canada balsam, Berlese, euparal, CMCP-10, Hoyer. The latter three media in this list have been frequently used in recent studies with great success. However, these preparations generally do not survive long-term museum storage. In preparing the slides, careful clearing, dissection and arrangement of each specimen is essential to enable identification to species. Folded wings, rotated heads, collapsed spermathecae, or lost antennae can prevent a secure final identification (WHO, 1975, 1979, 1980; Alexander, 2000; Marquardt et al., 2005).

\section{Identification}

The family Psychodidae is very old and maintains some of the most ancient dipteran characters. Members of the family are distinguished by a dense covering of narrow scales on head, thorax, legs and wing veins. Of the five psychodid subfamilies, only the Phlebotominae have piercing mouthparts capable of taking blood. Furthermore, the phlebotomines tend to have an elongate and more fragile structure, in contrast to a squatter and more robust appearance of the other psychodid flies. Phlebotomine sand flies are small with a body length seldom exceeding $3 \mathrm{~mm}$. Their colour ranges from almost white to almost black. Three features of phlebotomines are diagnostic to distinguish them from other Psychodidae: (1) when at rest, they characteristically hold their wings at an angle above the abdomen (fig. 9); (2) they are hairy; and (3) when alighting to engorge, they typically hop around on the host before settling down to bite.

The most important keys used for the morphological identification of sand flies are Theodor (1958), Artemiev (1980), Lewis (1982), Lane (1993), Abonnenc (1972) and the digital key entitled 'Sand Flies of the Afrotropical Region' prepared by Niang et al. (2004). There are also many incomplete (in 


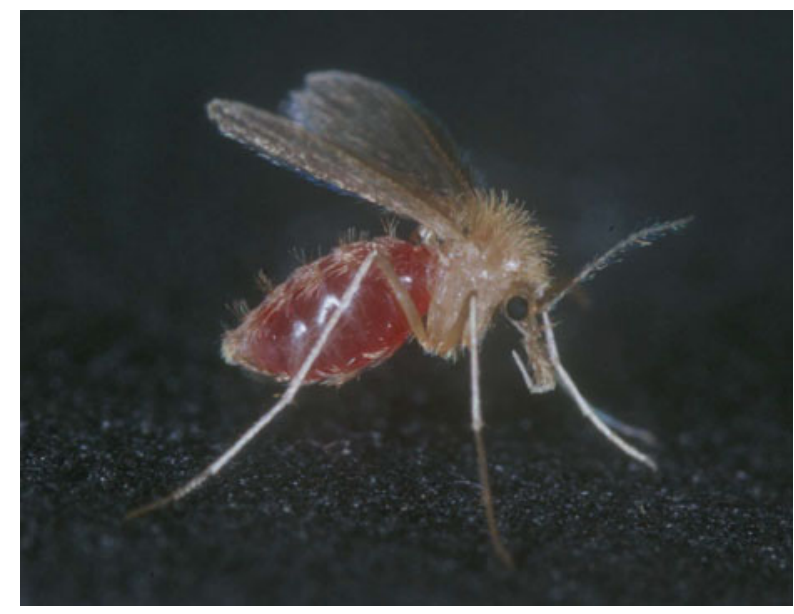

Fig. 9. Phlebotomus papatasi female: Photo credit: David Modry, Brno, Czech Republic.

many cases obsolete) written keys in the literature, and some of them are on local sand fly fauna for studied countries and/ or studied area(s). In fact, for most of the sand fly species, morphological identification is very difficult and needs experience, particularly for female specimens. The taxonomy is not always resolved and there are important gaps in our knowledge. In many cases, morphological identification using written keys is not sufficient, and molecular confirmation is additionally required. The best approach is to conduct a morphological identification and then to use molecular methods for confirmation. Even if most sand fly species can be distinguished morphologically it requires expertise to discern these differences. For instance, it is difficult to distinguish $P$. perniciosus from Phlebotomus longicuspis (Pesson et al., 2004) or Phlebotomus neglectus from Phlebotomus syriacus (Badakhshan et al., 2011; Erisoz Kasap et al., 2013). For damaged specimens and immature stages, molecular methods will be required for accurate identification.

One method is a DNA barcoding approach, involving PCR amplification and sequencing of a genetic region (e.g., ribosomal ITS2, nuclear EF-1 $\alpha$, mitochondrial cytochrome $b$, mitochondrial cytochrome oxidase subunit 1) which can be compared with sequences in an online database to identify the sand fly species (Latrofa et al., 2011; Erisoz Kasap et al., 2013; Gutiérrez et al., 2014). However, this is time consuming and requires access to specialist equipment. More rapid molecular methods for the identification and differentiation of sand fly species include (polymerase chain reaction) PCR of the ribosomal ITS2 region (Khalid et al., 2010; Latrofa et al., 2012) and PCR-RFLP (restriction fragment length polymorphism) of the mitochondrial DNA fragment $c y t b-n d 1$ (Latrofa et al., 2012) or $18 \mathrm{~S}$ ribosomal RNA gene (Tiwary et al., 2012). Both methods allow the separation of species based on differences in fragment sizes, and allow the identification of a large number of samples in a short time with limited resources. However, published protocols for these methods are usually region-specific and only cover a few common species. Recently, a MALDI-TOF (matrix-assisted laser desorption/ionization-time of flight) mass spectrometrybased method for the rapid identification of phlebotomine species has been developed (Dvorak et al., 2014), although currently this only covers five species and would require access to specialized equipment.

\section{Pathogen detection}

The phlebotomine sand flies are vectors of several zoonotic, or even anthroponotic, diseases such as leishmaniasis, bartonellosis and sandfly fever (Table 4). It must be recognized that the importance of the leishmaniases has eclipsed the possible role of sand flies in the transmission of other pathogens. The recent emergence of some of these diseases has led to a change in the view of sand flies as important disease vectors.

There are various methods that can be used to detect pathogens in sand flies. These methods include dissections (for Leishmania spp.), multiple locus electrophoresis (for Leishmania spp., Bartonella spp.), molecular detection including PCR, reverse transcriptase PCR, real-time PCR (for Leishmania spp., phlebovirus and bacteria) and in vitro cultivation and cell culture inoculation (Leishmania spp., phlebovirus and bacteria). Cultivation is cumbersome since the prevalence is very low for Leishmania spp. and phleboviruses. Prevalence can also show significant variation between different sand fly species and across an area. For example, in Italy Leishmania spp. prevalence in sand flies has been found to be $2.9 \%$ in Sicily (Goméz-Saladín et al., 2005) and $47.2 \%$ in Rome province (Rossi et al., 2008), whereas prevalence rates range from 0 to $78 \%$ in different regions of Spain (Martín-Sánchez et al., 2006; Alcover et al., 2012; Jiménez et al., 2013), and from 0 to $4 \%$ in Portugal (Branco et al., 2013; Maia et al., 2013). It is worth noting that Leishmania was detected more often in unfed versus blood-fed females (Jiménez et al., 2013). Phlebovirus infection rates have been recorded at $0.5 \%$ in Italy (Verani et al., 1988) and a study in France found that $9.1 \%$ of 66 pools of 30 sand flies were PCR-positive (Charrel et al., 2009).

Viral RNA detection via PCR and inoculation of cell cultures are the two most widely-used techniques for virus detection in sand flies. Once safe transportation is ensured, many methods including standard PCR or real-time PCR targeting a single pathogen (or many serotypes) can be employed according to the specific aims. See Marquardt et al. (2005) for detailed information.

If the pathogen has to be isolated, the viability of the organism in question has to be strictly preserved. To ensure this, samples must be kept cool as much as possible and must be transported in dry ice or liquid nitrogen. For nucleic acid detection, commercially available preservation solutions that inactivate nucleases can be employed. The best way to ensure viability is to keep the specimens alive until frozen in $-80^{\circ} \mathrm{C}$, if possible.

Pooling is frequently performed to increase the probability of detection in an endemic setting, to process a high number of specimens and to decrease screening costs. However, pooling may also decrease detection sensitivity if very few infected vectors are present in individual pools. Therefore, the decision of whether to use a pooling strategy should be based on the estimated prevalence of the pathogen in sand flies in the study region.

Blood-fed, gravid, or non-fed female sand flies are analysed for the detection of Leishmania spp. Nevertheless, the gravid and non-fed stages are more informative since they reflect the parasite's ability to survive in the sand fly after blood digestion, and thus the vectorial capacity of the sand fly species can be studied at the same time. For viruses with 
Table 4. Summary of diseases transmitted by sand flies.

\begin{tabular}{|c|c|c|}
\hline Disease & Pathogen details & Clinical perspective \\
\hline Leishmaniasis & $\begin{array}{l}\text { - Flagellate protozoa of the genus Leishmania } \\
\text { (Kinetoplastida, Trypanosomatidae), which infect } \\
\text { numerous mammalian species, including humans. } \\
\text { - Thirty different species: can be morphologically indis- } \\
\text { tinguishable, other characters have been used for their } \\
\text { taxonomy, mainly multilocus isoenzyme electrophor- } \\
\text { esis, and more recently molecular techniques (Bañuls } \\
\text { et al., 2007; Schönian et al., 2011). } \\
\text { - Widely distributed occurring in } 88 \text { countries, ranging } \\
\text { over the intertropical zones of America and Africa, and } \\
\text { extending into temperate regions of South America, } \\
\text { southern Europe and Asia. The limits of the disease are } \\
\text { latitudes } 45^{\circ} \mathrm{N} \text { and } 32^{\circ} \mathrm{S} \text {. } \\
\text { - Geographical distribution is governed by the limitations } \\
\text { of the sand fly vector or mammalian host species. }\end{array}$ & $\begin{array}{l}\text { - In humans, the disease may be visceral (VL), cutaneous } \\
\text { (CL), of localized (LCL) or diffuse (DCL) type, or muco- } \\
\text { cutaneous leishmaniasis (MCL) (Bañuls et al., 2011). } \\
\text { - The leishmaniases are diseases with natural focality. They } \\
\text { include several noso-epidemiological units, which can be } \\
\text { defined as the conjunction of a particular Leishmania spe- } \\
\text { cies, circulating in specific natural hosts, evolving in a } \\
\text { natural focus with specific ecological patterns, and having } \\
\text { a particular clinical expression. }\end{array}$ \\
\hline Phleboviruses & $\begin{array}{l}\text { - Phleboviridae is one of the five genera of the family } \\
\text { Bunyaviridae. They are members of the class V virus, } \\
\text { with segmented ambisense RNA genomes. } \\
\text { - Isolated in southern Europe, Africa, Central Asia and the } \\
\text { Americas (Alkan et al., 2013; Maroli et al., 2013). } \\
\text { - They include two groups: the Phlebotomus fever virus, } \\
\text { transmitted by phlebotomine sand flies (Alenquer, } \\
\text { Candiru, Chagres, sand fly fever Naples/Toscana, sand } \\
\text { fly fever Punta Toro, sand fly fever Sicilian, sand fly } \\
\text { fever Turkey virus) or by mosquitoes (Rift Valley fever } \\
\text { virus) and the Uukuniemi group, transmitted by ticks. } \\
\text { - Twenty-five phleboviruses have been isolated on the } \\
\text { American continent, reflecting the great diversity of the } \\
\text { New World sand flies. }\end{array}$ & $\begin{array}{l}\text { - Phleboviruses cause diseases ranging from short self- } \\
\text { limiting fevers to encephalitis and fatal haemorrhagic } \\
\text { fever. } \\
\text { - The phleboviruses Sicily and Toscana are responsible for } \\
\text { 'sand fly fevers', and are present in the Mediterranean } \\
\text { basin (Papa et al., 2006). } \\
\text { - Sand fly fevers are serious, but non-fatal, diseases. Most } \\
\text { common clinical presentation is flu-like symptoms, with } \\
\text { fever, headache, muscular pain, nausea, conjunctivitis and } \\
\text { photophobia. Meningitis and meningoencephalitis can } \\
\text { occasionally occur. Asymptomatic cases are frequent in } \\
\text { endemic country populations, particularly in populations } \\
\text { exposed to risk of sand fly bites, as shown in the Tuscany } \\
\text { region of Italy, where the seroprevalence in forestry } \\
\text { workers reached 77.2\%. } \\
\text { - The Toscana serotype of the Naples virus has regularly } \\
\text { been associated with central nervous system infections in } \\
\text { southern Italy and Sardinia, southern France, Spain, and } \\
\text { Portugal (Dionisio et al., 2001; Echevarria et al., 2003; Di } \\
\text { Nicuolo et al., 2005; Charrel et al., 2005; Charrel et al., 2007; } \\
\text { Santos et al., 2007; Sanbonmatsu-Gámez et al., 2009). } \\
\text { - Imported cases have also been reported in non-endemic } \\
\text { countries such as Germany (Imirzalioglu et al., 2006). } \\
\text { - Some vector species of the sand fly fevers have been } \\
\text { identified, such as P. papatasi in Italy, P. perniciosus in } \\
\text { Spain, Portugal and southern France, and P. major s.l in } \\
\text { Turkey (Konstantinou et al., 2007; Dedet, 2008; Ergunay } \\
\text { et al., 2012). }\end{array}$ \\
\hline
\end{tabular}

transovarial and transstadial transmission, both sexes are known to include viruses that can be efficiently detected. One approach is to identify virus sequences in blood-fed female sand flies and retain the males for morphologic identification and barcoding.

\section{Conclusion}

Unlike surveillance for mosquitoes or ticks, sampling for phlebotomine sand flies is much less practised in Europe. There may be many reasons for this, but undoubtedly the restricted range of sand flies to southern Europe has so far negated the need for surveillance in parts of central and northern Europe. However, with current climatic changes, and the evidence presented elsewhere on changes in sand fly distribution in Europe (Medlock et al., 2014), countries in previously non-endemic areas are becoming concerned about the prospect of a change in distribution both in latitude and altitude. Much of the expertise in sand fly sampling and surveillance in Europe exists with entomologists neighbouring the Mediterranean. This paper aims to share that expertise so that sand fly surveillance activities can be expanded to new locations in Europe, to further improve our understanding of the distribution of our native fauna, but also to better inform 
public and veterinary health risks assessments on sand flyborne disease.

\section{References}

Abonnenc, E. (1972) Les phlébotomes de la région Éthiopienne (Diptera, Psychodidae). Mém ORSTOM 55, 1-290.

Alcover, M.M., Gramiccia, M., Di Muccio, T., Ballart, C., Castillejo, S., Picado, A., Portús, M. \& Gállego, M. (2012) Application of molecular techniques in the study of natural infection of Leishmania infantum vectors and utility of sandfly blood meal digestion for epidemiological surveys of leishmaniasis. Parasitology Research 111(2), 515-523.

Alexander, B. (2000) Sampling methods for phlebotomine sand flies. Medical and Veterinary Entomology 14, 109-122.

Alkan, C., Bichaud, L., de Lamballerie, X., Alten, B., Gould, E.A. \& Charrel, R.N. (2013) Sandfly-borne phleboviruses of Eurasia and Africa: epidemiology, genetic diversity, geographic range, control measures. Antiviral Research 100(1), 54-74.

Anez, N. \& Tang, Y. (1997) Comparison of three methods for age grading of female Neotropical phlebotomine sand flies. Medical and Veterinary Entomology 11, 3-7.

Artemiev, M.M. (1980) A revision of sand flies of subgenus Adlerius (diptera, Phlebotominae, Phlebotomus). Zoologicheskii Zhurnal 59, 1177-1192 (in Russian).

Badakhshan, M., Sadraei, J. \& Moin-Vaziri, V. (2011) Morphometric and morphological variation between two different populations of Phlebotomus major s.l. from endemic and non-endemic foci of visceral leishmaniasis in Iran. Journal of Vector Ecology 36(1), 153-158.

Bañuls, A.L., Hide, M. \& Prugnolle, F. (2007) Leishmania and the leishmaniases: a parasite genetic update and advances in taxonomy, epidemiology and pathogenicity in humans. Advances in Parasitology 64, 1-109.

Bañuls, A.L., Bastien, P., Pomares, C., Arevalo, J., Fisa, R. \& Hide, M. (2011) Clinical pleomorphism in human leishmaniases, with special mention of asymptomatic infection. Clinical Microbiology and Infection 17(10), 1451-61.

Bowden, J. \& Morris, M.G. (1975) The influence of moonlight on catches of insects in light traps in Africa. The effective radius of a mercury-vapour light trap and the analysis of catches using effective radius. Bulletin of Entomological Research 65, 303-348.

Branco, S., Alves-Pires, C., Maia, C., Cortes, S., Cristovão, J.M., Gonçalves, L., Campino, L. \& Afonso, M.O. (2013) Entomological and ecological studies in a new potential zoonotic leishmaniasis focus in Torres Novas municipality, Central Region, Portugal. Acta Tropica 125(3), 339-348.

Charrel, R.N., Gallian, P., Navarro-Mari, M., Nicoletti, L., Papa, A. \& Sánchez-Seco, M.P. (2005) Emergence of Toscana virus in Europe. Emerging Infectious Diseases 11(11), 1657-1663.

Charrel, R.N., Izri, A., Temmam, S., Delaunay, P., Toga, I. \& Dumon, H. (2007) Cocirculation of 2 genotypes of Toscana virus, southeastern France. Emerging Infectious Diseases 13(3), 465-468.

Charrel, R.N., Moureau, G., Temmam, S., Izri, A., Marty, P., Parola, P., da Rosa, A.T., Tesh, R.B. \& de Lamballerie, X. (2009) Massilia virus, a novel Phlebovirus (Bunyaviridae) isolated from sandflies in the Mediterranean. Vector Borne and Zoonotic Disease 9(5), 519-530.

Dedet, J.P. (2008) The control of diseases transmitted by phlebotomine sandflies to humans, ever achievable? 3rd CVBD Symposium, 16-19 April 2008, Germany, proceeding 16-21.
Detinova, T.S. (1962) Age-Grouping Methods in Diptera of Medical Importance with Special Reference to Some Vectors of Malaria. WHO Monograph Series, 47, Geneva, World Health Organization.

Di Nicuolo, G., Pagliano, P., Battisti, S., Starace, M., Mininni, V., Attanasio, V. \& Faella, F.S. (2005) Toscana virus central nervous system infections in southern Italy. Journal of Clinical Microbiology 43, 6186-6188.

Dionisio, D., Valassina, M., Cuifolini, M.G., Vivarelli, A., Esperti, F. \& Cusi, M.G. (2001) Encephalitis without meningitis due to sandfly fever virus serotype Toscana. Clinical Infectious Disease 32(8), 1241-1243.

Disney, R.H. (1996) A trap for Phlebotomine sandflies attracted to rats. Bulletin of Entomological Research 56(3), 445-451.

Dvorak, V., Halada, P., Hlavackova, K., Dokianakis, E., Antoniou, M. \& Volf, P. (2014) Identification of phlebotomine sand flies (Diptera: Psychodidae) by matrix-assisted laser desorption/ionization time of flight mass spectrometry. Parasites and Vectors 7, 21.

Echevarria, J.M., de Ory, F., Guisasola, M.E., Sanchez-Seco, M. P., Tenorio, A. \& Lozano, A. (2003) Acute meningitis due to Toscana virus infection among patients from both the Spanish Mediterranean region and the region of Madrid. Journal Clinical Virology 26(1), 79-84.

Ergunay, K., Erisoz Kasap, O., Kocak Tufan, Z., Turan, M., Ozkul, A. \& Alten, B. (2012) Molecular Evidence Indicates That Phlebotomus major sensu lato (Diptera: Psychodidae) is the vector species of the recently-identified sandfly fever Sicilian virus variant: Sandfly Fever Turkey Virus. Vector-Borne Zoonotic Diseases 12(8), 690-698.

Erisoz Kasap, O., Belen, A., Kaynas, S., Simsek, F.M., Biler, L., Ata, N. \& Alten, B. (2009) Activity patterns of sand fly species (Diptera: Psychodidae) and comparative performance of different traps in an endemic CL focus in Cukurova Plain, Southern Anatolia. Acta Veterinaria Brno 78(2), 327-335.

Erisoz Kasap, O., Votypka, J. \& Alten, B. (2013) The Distribution of the Phlebotomus major (Diptera: Psychodidae) complex in Turkey. Acta Tropica 127(3), 204-211.

Espinola, H.N., Gonzalez, T.D., \& Tonn, R.J. (1983) A useful trap for collecting sand flies (Diptera: Psychodidae, Phlebotominae). Bulletin of the Society of Vector Ecology 8, 65-66.

Faiman, R., Cuño, R. \& Warburg, A. (2009) Comparative efficacy of three suction traps for collecting Phlebotomine sand flies (Diptera: Psychodidae) in open habitats. Journal of Vector Ecology 34, 114-118.

Feliciangeli, M.D. (2004) Natural breeding places of phlebotomine sandflies. Medical and Veterinary Entomology 18(1), 71-80.

Gómez-Saladín, E., Doud, C.W. \& Maroli, M. (2005) Short report: surveillance of Leishmania sp. among sand flies in Sicily (Italy) using a fluorogenic real-time polymerase chain reaction. American Journal of Tropical Medicine and Hygiene 72(2), 138-141.

Gressitt, J.L. \& Gressitt, M.K. (1962) An improved malaise trap. Pacific Insects 4, 87-90.

Gutiérrez, M.A.C., Vivero, R.J., Vélez, I.D., Porter, C.H. \& Uribe, S. (2014) DNA barcoding for the identification of sand fly species (Diptera, Psychodidae, Phlebotominae) in Colombia. PLoS One 9(1), e85496.

Hanson, W.J. (1961) The breeding places of Phlebotomus in Panama. Annals of the Entomological Society of America 54, 317-322.

Imirzalioglu, C., Schaller, M. \& Bretzel, R.G. (2006) Sandfly fever Naples virus (serotype Toscana) infection with meningeal 
involvement after a vacation in Italy. Deutsche Medizinische Wochenschrift 131, 2838-2840.

Jiménez, M., González, E., Iriso, A., Marco, E., Alegret, A., Fúster, F. \& Molina, R. (2013) Detection of Leishmania infantum and identification of blood meals in Phlebotomus perniciosus from a focus of human leishmaniasis in Madrid, Spain. Parasitology Research 112(7), 2453-2459.

Khalid, N., Elnaiem, D., Aboud, M., Al Rabba, F. \& Tripet, F. (2010) Morphometric and molecular differentiation of Phlebotomus (Phlebotomus) sandflies. Medical and Veterinary Entomology 24(4), 352-360.

Killick-Kendrick, R. (1999) The biology and control of phlebotomine sand flies. Clinics in Dermatology 17, 279-289.

Killick-Kendrick, R., Wilkes, T.J., Alexander, J., Bray, R.S., Rioux, J.-A. \& Bailly, M. (1985) The distance attraction of CDC light traps to phlebotominae sand flies. Annales De Parasitologie Humaine et Comparee 60, 763-767.

Kline, D., Hogsette, J.A. \& Müller, G. (2011) Comparison of various configurations of CDC-type traps for the collection of Phlebotomus papatasi Scopoli in southern Israel. Journal of Vector Ecology 36(Supplement 1), 212-218.

Konstantinou, G.N., Papa, A. \& Antoniadis, A. (2007) Sandflyfever outbreak in Cyprus: are phleboviruses still a health problem? Travel Medicine and Infectious Disease 5(4), 239-242.

Kuiper, G.P. (1938) The magnitude of the sun, the stellar temperature scale and bolometric corrections. Astrophysical Journal 88, 429-471.

Lane, R.P. (1993) Sand flies (Phlebotominae). in Lane, R.P. \& Crosskey, R.W. (eds) Medical Insects and Arachnids. London, Chapman and Hall, Ch. 4, 78-119.

Latrofa, M.S., Dantes-Torres, F., Weigl, S., Tarallo, V.D., Parisi, A., Traversa, D. \& Otranto, D. (2011) Multilocus molecular and phylogenetic analysis of phlebotomine sand flies (Diptera: Psychodidae) from southern Italy. Acta Tropica 119 (2-3), 91-98.

Latrofa, M.S., Annoscia, G., Dantas-Torres, F., Traversa, D. \& Otranto, D. (2012) Towards a rapid molecular identification of the common phlebotomine sand flies in the Mediterranean region. Veterinary Parasitology 184(2-4), 267-270.

Lewis, D.J. (1982) A taxonomic review of the genus Phlebotomus (Diptera: Psychodidae). Bulletin of the British Museum (Natural History), Entomology Series 52, 1-35.

Maia, C., Dionísio, L., Afonso, M.O., Neto, L., Cristóvão, J.M. \& Campino, L. (2013) Leishmania infection and host-blood feeding preferences of phlebotomine sandflies and canine leishmaniasis in an endemic European area, the Algarve Region in Portugal. Memorias do Instituto Oswaldo Cruz 108(4), 481-487.

Maroli, M., Feliciangeli, M.D. \& Arias, J. (1997) Metodos de captura, conservacion y montaje de los flebotomos (Diptera: Psychodidae). Documenio OPS/HCP/HCT/95/97. Washington, DC, Organizacion Panamericana de la Salud.

Maroli, M., Feliciangeli, M.D., Bichaud, L., Charrel, R.N. \& Gradoni, L. (2013) Phlebotomine sandflies and the spreading of leishmaniases and other diseases of public health concern. Medical and Veterinary Entomology 27(2), 123-147.

Marquardt, W.C., Black, W.C., Freier, J., Hagedorn, H.H., Hemingway, J., Higgs, S., James, A.A., Kondratieff, B. \& Moore, C.G. (2005) Biology of Disease Vectors. 2nd edn. Elsevier Academic Press, China, 785 p.

Martin, F.R., McCreadie, J.W. \& Colbo, M.H. (1994) Effect of trap site, time of day, and meteorological factors on abundance of host-seeking mammalophilic Black Flies (Diptera: Simulidae). The Canadian Entomologist 126, 283-289.
Martín-Sánchez, J., Gállego, M., Barón, S., Castillejo, S. \& Morillas-Marquez, F. (2006) Pool screen PCR for estimating the prevalence of Leishmania infantum infection in sandflies (Diptera: Nematocera, Phlebotomidae). Transactions of the Royal Society of Tropical Medicine and Hygiene 100(6), 527-532.

McCombie-Young, T.C., Richmond, A.E. \& Brendish, G.R. (1926) Sand flies and sand fly fever in the Peshawar district. Indian Journal of Medical Research 13, 961-1021.

Medlock, J.M., Hansford, K.M., Van Bortel, W., Zeller, H. \& Alten, B. (2014) A summary of the evidence for the change in European distribution of phlebotomine sand flies (Diptera: Psychodidae) of public health importance. Journal of Vector Ecology 39(1), 72-77.

Moncaz, A., Faiman, R., Kirstein, O. \& Warburg, A. (2012) Breeding Sites of Phlebotomus sergenti, the Sand Fly. Vector of Cutaneous Leishmaniasis in the Judean Desert. PLoS Neglected Tropical Diseases 6(7), e1725.

Montoya-Lerma, J. \& Lane, R.P. (1996) Factors affecting host preference of Lutzomyia evansi (Diptera: Psychodidae) a vector of visceral leishmaniasis in Colombia. Bulletin of Entomological Research 86, 43-50.

Moore, C.G. \& Gage, K.L. (1996) Collecting methods for vector surveillance. pp. 471-491. in Beatty, B.J. \& Marquardt, W.C. (ed) The Biology of Disease Vectors. Niwot, CO, University Press of Colorado.

Niang, A.A., Hervy, J.-P., Depaquit, J., Bousses, P., Davidson, I., Geoffroy, B., Leger, N., Trouillet, J., Killick-Kendrick, R., Killick-Kendrick, M., Rioux, J.-A. \& Brunches, J. (2004) Sand flies of the Afrotropical region. CD-ROM. IRD/IFAN, IRD Editions.

Papa, A., Konstantinou, G., Pavlidou, V. \& Antoniadis, A. (2006) Sandfly fever virus outbreak in Cyprus. Clinical Microbiology and Infection 12(2), 192-194.

Pesson, B., Ready, J.S., Benabdennbi, I., Martín-Sánchez, I., Esseghir, S., Cadi-Soussi, M., Morillas-Marquez, F. \& Ready, P.D. (2004) Sandflies of the Phlebotomus perniciosus complex: mitochondrial introgression and a new sibling species of $P$. longicuspis in the Moroccan Rif. Medical and Veterinary Entomology 18(1), 25-37.

Rossi, E., Bongiorno, G., Ciolli, E., Di Muccio, T., Scalone, A., Gramiccia, M., Gradoni, L. \& Maroli, M. (2008) Seasonal phenology, host-blood feeding preferences and natural Leishmania infection of Phlebotomus perniciosus (Diptera, Psychodidae) in a high-endemic focus of canine leishmaniasis in Rome province, Italy. Acta Tropica 105(2), 158-165.

Rutledge, L.C. \& Mooser, H.L. (1972) Biology of immature sand flies (Diptera: Psychodidae) at the bases of trees in Panama. Environmental Entomology 1, 300-309.

Sanbonmatsu-Gámez, S., Pérez-Ruiz, M., Palop-Borrás, B. \& Navarro-Marí, J.M. (2009) Unusual manifestation of Toscana virus infection, Spain. Emerging Infectious Diseases 15(2), 347-348.

Santos-De Marco, T., De Mello Gaia, M.C. \& Peçanha Brazil, R. (2002) Influence of the lunar cycle on the activity of phlebotomine sand flies (Diptera: Psychodidae). Journal of the American Medical Association 18(2), 114-118.

Santos, L., Simões, J., Costa, R., Martins, S. \& Lecour, H. (2007) Toscana virus meningitis in Portugal, 2002-2005. Eurosurveillance 12(6), 125-127.

Schönian, G., Kuhls, K. \& Mauricio, I.L. (2011) Molecular approaches for a better understanding of the epidemiology and population genetics of Leishmania. Parasitology 138(4), 405-425. 
Service, M.W. (1993) Mosquito Ecology: Field Sampling Methods. London, Chapman and Hall. p. 482.

Southwood, T.R.E. \& Henderson, P.A. (2000) Ecological Methods. 3rd edn. Blackwell Science, p. 575.

Thatcher, V.E. (1968) Arboreal breeding sites of phlebotomine sand flies in Panama. Annals of the Entomological Society of America 61, 1141-1143.

Theodor, O. (1958) Psychodidae-Phlebotominae. pp. 1-55. in Lindner, E. (ed) Die Fliegen der Palaerktischen Region. Stuttgart, Germany, E. Schweizerbart'sche.

Tiwary, P., Kumar, D., Rai, M. \& Sundar, S. (2012) PCR-RFLP based method for molecular differentiation of sand fly species Phlebotomus argentipes, Phlebotomus papatasi, and Sergentomyia babu found in India. Journal of Medical Entomology 49(6), 1515-1518.

Townes, H. (1962) Design for a Malaise trap. Proceedings of the Entomological Society of Washington 64, 253-262.

Valenta, D.T., Tang, Y. \& Anez, N. (1995) A new method to determine the distance at which phlebotomine sand flies are attracted to light under field conditions. Proceedings of the 2nd International Symposium on Phlebotomine Sand Flies (ISOPS II) Merida, Venezuela. Boletin de la Direccion de Malariologia y Saneamiento Ambiental 35(Supplementary 1), 353-358.
Verani, P., Ciufolini, M.G., Caciolli, S., Renzi, A., Nicoletti, L., Sabatinelli, G., Bartolozzi, D., Volpi, G., Amaducci, L., Coluzzi, M., Paci, P. and Balducci, M., et al. (1988) Ecology of viruses isolated from sand flies in Italy and characterized of a new Phlebovirus (Arabia virus). American Journal of Tropical Medicine and Hygiene 38(2), 433-439.

Veronesi, E., Pilani, E., Carrieri, R. \& Bellini, R. (2007) Trapping sandflies (Diptera: Psychodidae) in the Emilia-Romagna region of Northern Italy. Journal of Vector Ecology 32, 313-318.

Volf, P. \& Volfova, V. (2011) Establishment and maintenance of sand fly colonies. Journal of Vector Ecology 36(Supplement 1), S1-S9.

WHO (1975) Manual on Practical Entomology in Malaria, Part II. Geneva, WHO Offset Publication, $191 \mathrm{p}$.

WHO (1979) Studies on Leishmaniasis Vectors/Reservoirs and Their Control in the World, General Review and Inventory. WHO/ VBC/79.749, Geneva, 88 p.

WHO (1980) Studies on Leishmaniasis Vectors/Reservoirs and Their Control in the World, Part III: Middle East. WHO/VBC/ 80.776, Geneva, 78 p.

Yaghoobi-Ershadi, M.R. \& Javadian, E. (1996) Seasonal variation of Leishmania major infection rates in sand flies from rodent burrows in Isfahan Province, Iran. Medical and Veterinary Entomology 10, 181-184. 